\title{
New Concept for Correction of Brachymetatarsy by 3D CT-Scan Measurement
}

\section{Fanny Alkar*, Francois Bonnel, Djamel Louahem M Sabah, Philippe Mazeau and Jerome Cottalorda}

Paediatric Orthopaedic Surgery Unit, Centre Hospitalier Universitaire Lapeyronie, Montpellier, France

\begin{abstract}
We reported progressive metatarsal lenghtening by external fixator after osteotomy by open approach without bone interposition in a case of brachymetatarsia upon the third and fourth metatarsals. After a tomodensitometry planification, the biometry of the five metatarsal bones was done by X-ray and CT scan by measuring each metatarsal length (1 to 5 ) in the sagittal, horizontal and coronal plans and angles. The average amount of lengthening was 17 $\mathrm{mm}$ for the third and $15 \mathrm{~mm}$ the fourth at the end, $40 \%$ of the original length (range, 36 to $44 \%$ ). In the same time, we treated hallux valgus by osteotomy. Decrease of motion and joint deformity did not occur. The control of the CT scan allowed choosing the real orientation and length of the two metatarsal bones to obtain an adequate parabola. Measurements with CT scan were more reliable than Xray.
\end{abstract}

Keywords: Congenital brachymetatarsia; Callotasis; Tomodensitometry planification; Bone lengthening

\section{Introduction}

The operative corrections of brachymetatarsia may sometimes lead to complications and lengthening procedure is the best choice [1] One-stage lengthening with an interpositional bone graft or gradual lengthening by callotasis are the two most widely used techniques [2,3]. For brachymetatarsia, numerous variables must be assessed, including the number of rays affected, the associated deformities, the soft-tissue contracture, and the tension of the skin. The measurement of the length by a preoperative CTscan has not been used before [4].

Our aim was to evaluate tomodensitometry planification and metatarsal lengthening by external fixator.

\section{Materials and Methods}

\section{Case report}

We report the case, with informed consentment, of 10-year-old girl and her family with a congenital bilateral deformity of the forefoot including brachymetatarsia of the third and fourth rays with hallux valgus (Figure 1). The genetic investigation found no mutation of collagen 2 (spondylo epiphyseal dysplasia). The indication was painwearing shoes, and cosmetic and psychological concern.

The examination of the left and right foot showed a normal walk and a podoscopic flat footprints grade 1 without metatarsalgia. There was no pain during examination with ankle range of motion $45^{\circ}$, dorsiflexion and $50^{\circ}$ plantar flexion. The second, fourth and fifth metatarsal ranges of motion were normal. The motion of the third metatarsophalangeal joint of the left foot was $0^{\circ}$ of active dorsiflexion and $45^{\circ}$ of plantarflexion. Bilateral hallux were entirely reducible with $35^{\circ}$ of dorsiflexion and $40^{\circ}$ of plantar flexion.

On charge X-ray with inclination of $10^{\circ}$ dorsoplantar, we noted brachymetatarsia of the third and the fourth ray associated with hallux valgus (Figure 2) and, on a sagittal plan, a bilateral posterior talocalcaneal coalition. The clinical metatarsophalangeal angle of the left first ray was $50^{\circ}$ on X-ray. We performed a bilateral CTscan analysis in discharge of the feet before surgery (Figure 3), and pictures in DICOM format were analyzed and biometry of the five metatarsals by the Myriam ${ }^{\circledR}$ specific software (Intrasense ${ }^{\circledR C E}$ ). The AOFAS score was performed.

\section{Measurements}

On X-ray, we measured, on dorsoplantar view, the length of each metatarsal bone. On lateral X-ray, we measured the sagittal angle of the first and the fifth metatarsal bones. The lengths of the left metatarsals are mentioned on table 1 . Bilateral hallux valgus was present. The first metatarsophalangeal angle M1P1 was $60^{\circ}$, first and second metatarsal M1M2 angle was $17^{\circ}$

On CT scan, we measured each metatarsal length (1 to 5$)$ in the sagittal and horizontal plans, on the coronal plan the torsional angle of the metatarsal, the first metatarsophalangeal angle M1P1 and the first and second metatarsal angle M1M2 of each foot. The results allowed us to decide the adequate lengthening of all metatarsal bones to obtain a good metatarsal parabola.

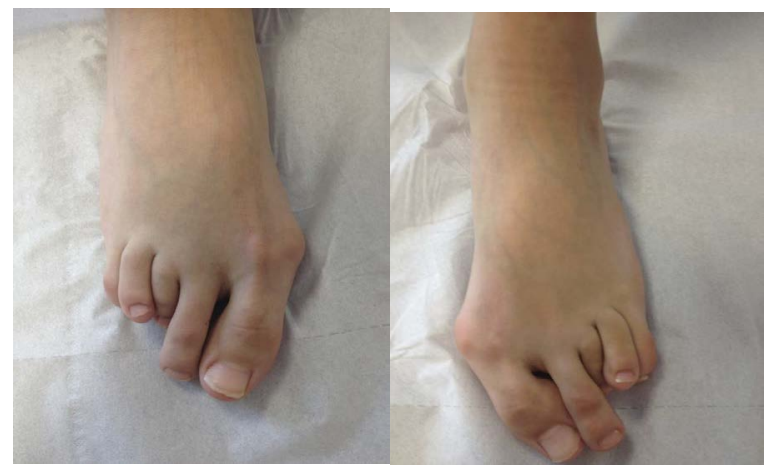

Figure 1: Dorsal view of a bilateral congenital deformity of the feet with hallux valgus and brachymetatarsia.

*Corresponding author: Fanny Alkar, Paediatric Orthopaedic Surgery Unit Centre Hospitalier Universitaire Lapeyronie, Montpellier, France, Tel: +3346733 87 61; Fax: +33 4675246 44; E-mail: fanny.alkar@gmail.com

Received June 16, 2014; Accepted July 14, 2014; Published July 21, 2014

Citation: Alkar F, Bonnel F, Sabah DLM, Mazeau P, Cottalorda J (2014) New Concept for Correction of Brachymetatarsy by 3D CT-Scan Measurement. J Biosens Bioelectron 5: 156. doi: 10.4172/2155-6210.1000156

Copyright: (๑) 2014 Alkar F, et al. This is an open-access article distributed under the terms of the Creative Commons Attribution License, which permits unrestricted use, distribution, and reproduction in any medium, provided the original author and source are credited. 
Citation: Alkar F, Bonnel F, Sabah DLM, Mazeau P, Cottalorda J (2014) New Concept for Correction of Brachymetatarsy by 3D CT-Scan Measurement. J Biosens Bioelectron 5: 156. doi: 10.4172/2155-6210.1000156

\begin{tabular}{|l|c|c|c|c|}
\hline \multirow{2}{*}{ Metatarsal length } & \multicolumn{2}{|c|}{ Preoperative } & \multicolumn{2}{c|}{ Postoperative } \\
\cline { 2 - 5 } & Radiograph & CT scan & Radiograph & CT scan \\
\hline First & 49 & 50 & 48 & 50 \\
\hline Second & 50 & 57 & 51 & 55 \\
\hline Third & 36 & 38 & 53 & 52 \\
\hline Fourth & 36 & 36,4 & 49 & 49 \\
\hline Fifth & 44 & 47 & 49 & 47 \\
\hline
\end{tabular}

* In millimeter

Table 1: Left foot radiograph and CT scan measurements pre and postoperative in millimeters of the five metatarsal bones on dorsoplantar plan.

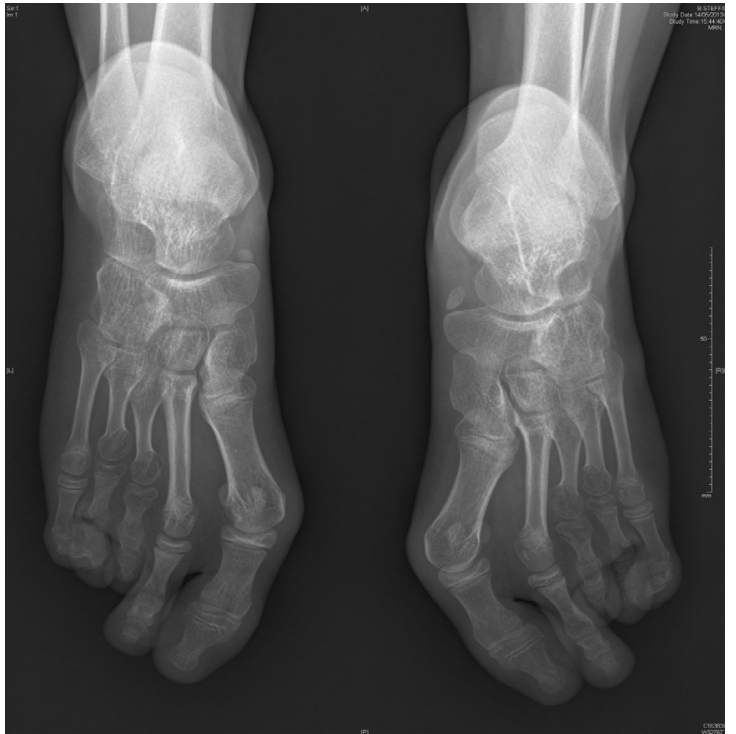

Figure 2: Xray of bilateral brachymetatarsia of the third and fourth rays.

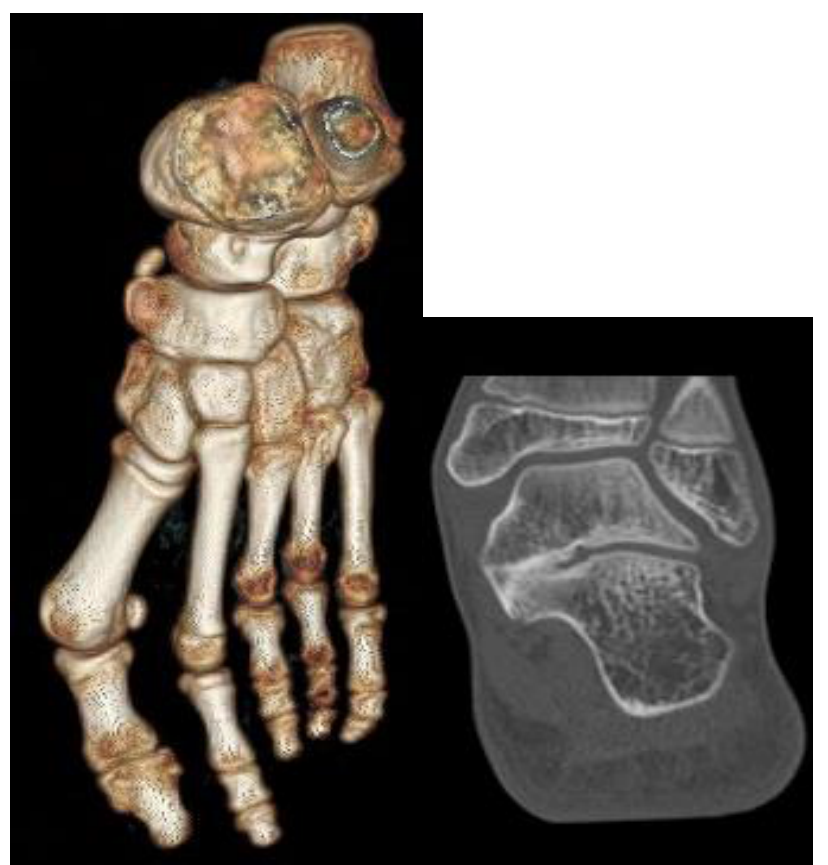

Figure 3: CTscan showing hallux valgus, brachymetatarsia of the third and the fourth ray and posterior talocalcaneal coalition.

\section{Operative objectives}

The operative technique for the left foot was to lengthen the third and the fourth metatarsal (17 and $15 \mathrm{~mm}$ ), to shorten the second metatarsal $(8 \mathrm{~mm})$ and treat the hallux valgus using the scarf procedure. The coalition was not treated at the same time.

\section{Surgery procedure}

The surgery was performed on the left foot (tourniquet $200 \mathrm{mmHg}$ ). The dorsal approach of the diaphysis of the third and the fourth metatarsal was done under periostal. Four self-tapping $2 \mathrm{~mm}$ threaded pins were inserted in the diaphysis using a special guide. The pins were implanted at $5 \mathrm{~mm}$ of the adjacent joints (metatarsophalangeal and cuneometatarsal). Between 2 pins, the distance was 8 to $10 \mathrm{~mm}$. Transverse medial osteotomy was carried out between the second and third pin. The proximal and distal fragments were held in the right position by an unilateral minirail external fixator (Orthofix ${ }^{\bullet} \mathrm{M}-100$ ) without axial pin. Two external fixators were positioned on the third and the fourth metatarsal bones. No distraction or bone interposition was made on the third and the fourth metatarsal. The periosteum was sutured with release of the extensor digitorum brevis tendon. Shortening osteotomy of $3 \mathrm{~mm}$ of the second metatarsal was performed with an axial pin osteosynthesis. Hallux valgus was treated using the scarf osteotomy technique. Non weight bearing on crutches was allowed until 3 months after surgery and the patient was discharged from the hospital 10 days later. Distraction began 10 days after surgery by the girl herself to obtain a lengthening of $0.5 \mathrm{~mm}$ every 12 hours until reaching 17 and $15 \mathrm{~mm}$ respectively for the third and the fourth metatarsal. Callus formation around the osteotomy gap was checked radiographically every 2 weeks (Figure 4 ).

Distraction was continued until the third and the fourth metatarsal and toes were in normal position to reach target length at one month. A control CT scan was performed at 6 months.

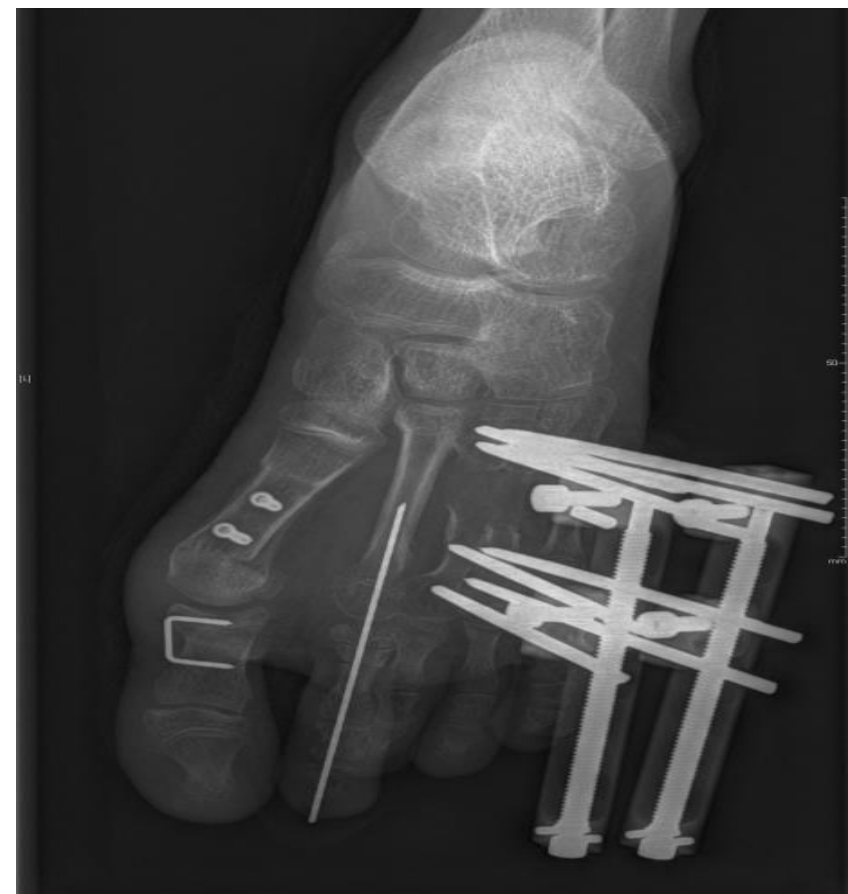

Figure 4: Post operative X-ray control (21 days) with the external fixator. 


\section{Results}

In postoperative care, there was no complication and the pain was treated by oral antalgic. Outcome was favorable with a correct psychological acceptation of the treatment. The final increase in length was $17 \mathrm{~mm}$ for the third and $15 \mathrm{~mm}$ for the fourth metatarsal. The axial pin of the second metatarsal was removed at the end of the third week. The external fixators were removed under anesthesia 60 days after bone healing (Figure 5).

At 8 months, the cosmetic result was good (Figure 6) except for a dorsal scar. The patient was able to wear shoes without pain. At this time, the ankle range of motion was $45^{\circ}$ dorsiflexion and $50^{\circ}$ plantarflexion. The third metatarsal joint of the left foot was $5^{\circ}$ of active dorsiflexion and $40^{\circ}$ of plantarflexion. The range of motion of the first ray was corrected with $25^{\circ}$ of dorsiflexion and $25^{\circ}$ of plantarflexion. The AOFAS lesser toes metatarsophalangeal interphalangeal score was 20 points preoperatively and 77 points postoperatively at the last available follow-up at 6 months on the left foot.

\section{Discussion}

Brachymetatarsia is chiefly a cosmetic problem due to the deformity of the forefoot. Surgery is not performed before 10 years of age, waiting for more bone growth and better acceptation from the children.

Many techniques of lengthening by callus distraction were described as a method for lengthening long bone by progressive, axial distraction of diaphyseal callus.

Authors [2] performed one-stage lengthening using intercalary autogenous bone graft. Choi et al. [2], showed the advantages of onestage lengthening with intercalary bone graft over gradual lengthening by callotasis including shorter period of consolidation, lesser scar and better psychological acceptation. The disadvantages included donorsite morbidity and neurovascular impairment by rapid stretching. It was difficult to obtain the metatarsal parabola owing to the initial

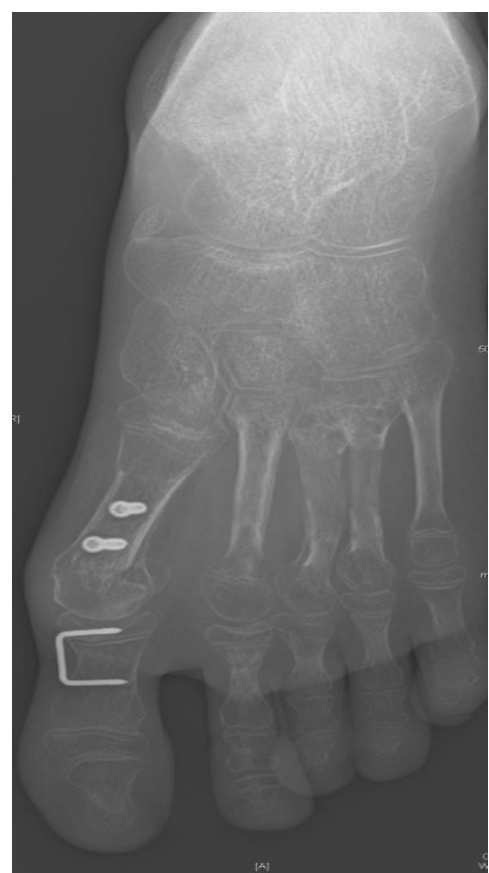

Figure 5: Post operative Xray (10 days after removing external fixator).

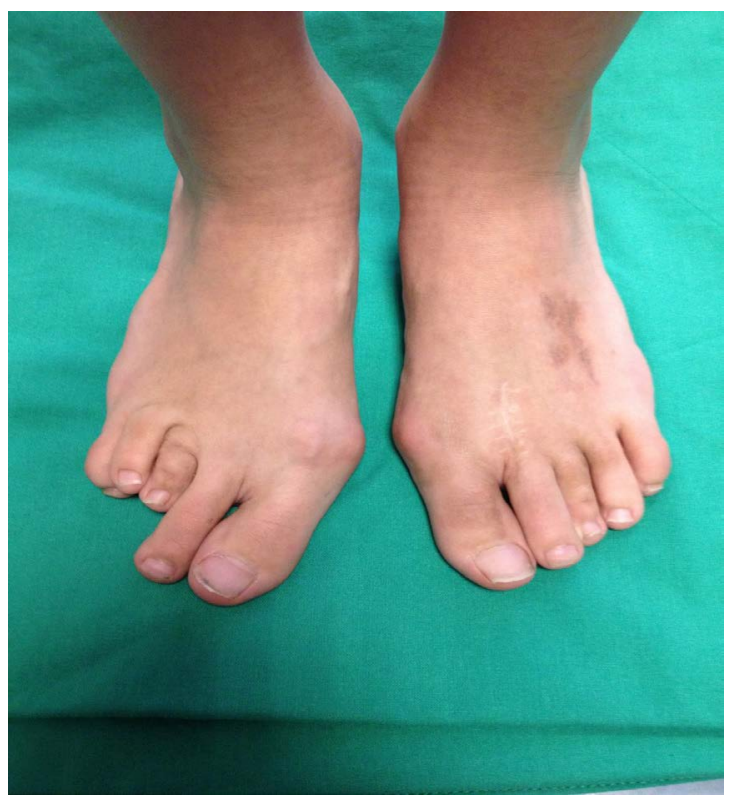

Figure 6: Dorsal view at 8 month.

length with the graft. Moreover, intraoperative gradual distraction was stopped by the high tension exerted to surrounding soft tissues. However, the same authors believed that lengthening by callotasis was more effective and safer when multiple and longer lengthening were required. Giannini [4] reported 41 feet (29 patients with a mean follow-up of 5 years) with one-stage metatarsal lengthening by allograft interposition and reported five cases of lack of lengthening with regard to the metatarsal parabola. Recently, Desai [5] proposed a modified surgical technique using bone graft with a lengthening scarf osteotomy. This osteotomy secured the fixation, decreased the chance of shortening post operatively and did not require another surgical time for removing a wire. The problem was the limitation of distraction $(9 \mathrm{~mm})$.

The procedure of leg progressive lengthening was firstly described by Ilizarov et al. [6] with many advantages [7]. For metatarsal, this procedure minimizes the stress of soft tissues such as neurovascular ones and adapts the length when the metatarsal regains [8-13]. The increase in length of the metatarsal bones was adequate for correction of the deformities, and the strength of the elongated bones was sufficient to withstand normal sport activities $[14,15]$. The psychological and emotional aspects of the external distraction must be considered [2] as well as the long time for bone healing, management, limitations, hypertrophic scar. The reported complications during callus distraction were subluxation of the metatarsophalangeal joint, flexion deformity of the toes, limitation of the range of motion, premature healing, callus fracture, deviation of the metatarsal $[1,8,12,13,16-18]$. To prevent deformity, a temporary axial pin fixation was used [16]. Kim et al. [19] proposed the association of shortening an adjacent bone if the target length is more than $15 \mathrm{~mm}$ in order to reduce the period of treatment and to avoid complications.

For lengthening short metatarsal bones, the callotasis method seemed preferable to other procedures requiring bone grafts [17,20-22] or artificial implants [23-25] because of the complexity of the deformity with hallux valgus. There was no sign of bone resorption or reshortening at 3 months follow-up. Scher [26] modified the surgical technique with external fixator using an axial transarticular K-wire incorporated in the external fixator in one case. The principal advantage was to avoid 
complications like pin infection. However, this procedure needs a good cooperation from the patient. The choice of the technique depends on the length to obtain.

For Kim et al. [3], the preoperative plan permits to choose the technique for lengthening or shortening if the target length is more than $15 \mathrm{~mm}$. So they used a dorsoplantar radiography to determine the site for bone shortening after analysis of the metatarsal and phalanx. We think that the X-ray measurement method was inaccurate. CT scan analysis obtained an exact length. The measurement by CT scan was superior to $\mathrm{X}$-ray. With our technique it was important to planify exactly the target lengthening and the correction of all the deformations. The CT scan allowed a complete pre-evaluation of the complex deformity and a real length evaluation comparatively to the $\mathrm{X}$-ray, which was insufficient for medial metatarsals. Giannini [4] measured the length needed to restore the metatarsal parabola on a dorsoplantar radiography. Therefore they explain that CT and MRI are more reliable but too expensive. In our case, the CT scan allowed to planify precisely the target length and to check the associated deformation. Lida and Watanabe [27] used 3D CT data to planify the correction of brachymetatarsia (22 year old woman) to build a model of graft with hydroxyapatite for the target lengthening. The disadvantage was the irradiation. The result was According to the AOFAS score the result was 22 points preoperative and 77 points at the last followup. The mean postoperative AOFAS score was 88 points (74-96 points) for Giannini [4] with a percentage of improvement of $76 \%$.

\section{Conclusion}

The use of CT scan with preoperative planning of target length permits to define more precisely the length before and during elongation. The external fixator is the best technique for elongation over $15 \mathrm{~mm}$ because it is more effective and can be used by percutaneous technique. We recommend a correction of the complex deformity of the forefoot in one-stage surgery using callotasis lengthening for brachymetatarsy. Moreover, our data suggest that a CT scan analysis of the complex deformity before beginning correction is necessary to detect all the associated deformations and to make a precise planification. The complex deformity can be corrected in one stage surgery but needs frequent postoperative care.

\section{Conflict of Interest}

\section{None}

\section{References}

1. Fox IM (1998) Treatment of brachymetatarsia by the callus distraction method. J Foot Ankle Surg 37: 391-395.

2. Choi IH, Chung MS, Baek GH, Cho TJ, Chung CY (1999) Metatarsal lengthening in congenital brachymetatarsia: one-stage lengthening versus lengthening by callotasis. J Pediatr Orthop 19: 660-664.

3. Kim HT, Lee SH, Yoo Cl, Kang JH, Suh JT (2003) The management of brachymetatarsia. J Bone Joint Surg Br 85: 683-690.

4. Giannini S, Faldini C, Pagkrati S, Miscione MT, Luciani D (2010) Onestage metatarsal lengthening by allograft interposition: a novel approach for congenital brachymetatarsia. Clin Orthop Relat Res 468: 1933-1942.

5. Desai A, Lidder S, R Armitage A, S Rajaratnam S, D Skyrme A (2013) Brachymetatarsia of the fourth metatarsal, lengthening scarf osteotomy with bone graft. Orthop Rev (Pavia) 5: e21.

6. Ilizarov GA, Lediaev VI, Shitin VP (1969) [The course of compact bone reparative regeneration in distraction osteosynthesis under different conditions of bone fragment fixation (experimental study)]. Eksp Khir Anesteziol 14: 3-12.

7. Ilizarov GA, Deviatov AA, Trokhova VG (1972) [Surgical lengthening of the shortened lower extremities]. Vestn Khir Im I I Grek 108: 100-103.
8. De Bastiani G, Aldegheri R, Renzi-Brivio L, Trivella G (1987) Limb lengthening by callus distraction (callotasis). J Pediatr Orthop 7: 129-134.

9. Levine SE, Davidson RS, Dormans JP, Drummond DS (1995) Distraction osteogenesis for congenitally short lesser metatarsals. Foot Ankle Int 16: 196200

10. Magnan B, Bragantini A, Regis D, Bartolozzi P (1995) Metatarsal lengthening by callotasis during the growth phase. J Bone Joint Surg $\mathrm{Br} 77: 602-607$.

11. Shim JS, Park SJ (2006) Treatment of brachymetatarsia by distraction osteogenesis. J Pediatr Orthop 26: 250-254

12. Wakisaka T, Yasui N, Kojimoto H, Takasu M, Shimomura Y (1988) A case of short metatarsal bones lengthened by callus distraction. Acta Orthop Scand 59: 194-196.

13. Wilusz PM, Van P, Pupp GR (2007) Complications associated with distraction osteogenesis for the correction of brachymetatarsia: a review of five procedures. $J$ Am Podiatr Med Assoc 97: 189-194.

14. Robinson JF, Ouzounian TJ (1998) Brachymetatarsia: congenitally short third and fourth metatarsals treated by distraction lengthening--a case report and literature summary. Foot Ankle Int 19: 713-718.

15. Houshian S, Skov O, Weeth RE (2002) Correction of congenital brachymetatarsia by gradual callus distraction. Scand J Plast Reconstr Surg Hand Surg 36: 373-375.

16. Song HR, Oh CW, Kyung HS, Kim SJ, Guille JT, et al. (2003) Fourth brachymetatarsia treated with distraction osteogenesis. Foot Ankle Int 24: 706711.

17. Masada K, Fujita S, Fuji T, Ohno H (1999) Complications following metatarsa lengthening by callus distraction for brachymetatarsia. J Pediatr Orthop 19 394-397.

18. Urano Y, Kobayashi A (1978) Bone-lengthening for shortness of the fourth toe J Bone Joint Surg Am 60: 91-93.

19. Yamada N, Yasuda Y, Hashimoto N, Iwashiro H, Uchinuma E (2005) Use of internal callus distraction in the treatment of congenital brachymetatarsia. $\mathrm{Br}$ Plast Surg 58: 1014-1019.

20. Kim JS, Baek GH, Chung MS, Yoon PW (2004) Multiple congenita brachymetatarsia. A one-stage combined shortening and lengthening procedure without iliac bone graft. J Bone Joint Surg Br 86: 1013-1015.

21. Lamm BM (2010) Percutaneous distraction osteogenesis for treatment of brachymetatarsia. J Foot Ankle Surg 49: 197-204.

22. Kaplan EG, Kaplan GS (1978) Metatarsal lengthening by use of autogenous bone graft and internal wire compression fixation: a preliminary report. J Foot Surg 17: 60-66.

23. McGlamry ED, Fenton CF 3rd (1983) Brachymetatarsia. A case report. J Am Podiatry Assoc 73: 75-78.

24. Yonenobu K, Takaoka K, Tsuyuguchi Y, Ono K, Tada K (1986) Elongation of brachymetatarsy with ceramic implant: a roentgenographic evaluation of its utility. J Biomed Mater Res 20: 1249-1256.

25. Mah KK, Beegle TR, Falknor DW (1983)A correction for short fourth metatarsal. J Am Podiatry Assoc 73: 196-200.

26. Scher DM, Blyakher A, Krantzow M (2010) A modified surgical technique for lengthening of a metatarsal using an external fixator. HSS J 6: 235-239.

27. lida N, Watanabe A (2013) A new surgical procedure for brachymetatarsia by a hydroxyapatite graft. Eur J Plast Surg. 36:41-44. 